\title{
A Case Study in Corporate Social Responsibility
}

\author{
Sharon K. Kendrick, Mark C. Kendrick \\ Methodist University, Fayetteville, NC \\ Anastasiya Saakova \\ Breast Cancer Detection Center, Fairbanks, AK
}

\begin{abstract}
This case study promotes analysis through a brief investigation into the role of corporate social responsibility (CSR) in the operation of a multinational corporation as evidenced by Google, Inc. The study focuses on a transnational company in order to observe the impact of CSR practice on a global level. The study will present implications of CSR for corporate management, corporate employees, state regulators, shareholders, and customers in general. In addition, the study will discuss consequences of poor CSR compliance for a multinational corporation. Questions for analysis include implications of CSR, employee retention, development of corporate culture, and evaluation of advantages and disadvantages of different CSR approaches. Upon conclusion of the study, suggestions are made for future collaborative efforts in corporate social responsibility as applied to psychological, sociological, and economical motives. Recruiting and training possibilities also present partnership opportunities for best practice sharing in regards to community, civic, and service engagement.
\end{abstract}

Keywords: Corporate social responsibility, Google, transnational, multinational, corporate culture, human rights, philanthropy, Uzbekistan, censorship, filtering, ideology

\section{A CASE STUDY IN CORPORATE SOCIAL RESPONSIBILITY}

Corporate social responsibility is a concept that has gained prominence over the past decade. A growing number of large companies have adopted 'green' policies and have implemented sustainable methods and techniques in their operations. It is a general practice among large transnational corporations to seek ways to reach out and help communities around the world that face significant challenges due to exploitation and violation of human rights, poverty, hunger, absence of effective health care systems, lack of quality education, and other causes. For the purpose of this case study analysis, the following description was used as a definition of corporate social responsibility: "A business's intention, beyond its legal and economic obligations, to do the right things and act in ways that are good for society" (Coulter \& Robbins, 2011).

The business entity selected for this study was Google, Inc. As a company, Google is a transnational organization that made it to the Fortune Magazine's World's Most Admired Companies in 2009. Google applied social responsibility and made it one of its business priorities. In 2006 one of the founders of the company, Larry Page, made a promise to allocate about 1 percent of Google's profits, 1 percent of its equity, and a significant amount of its employees' time and effort to help tackle the world's problems (Strom \& Helft, 2011). To envelope a CSR role, this case study used selected services (Search, AdWords, Google philanthropy Projects) and analyzed social impact, benefit, and concerns related to the terms of services, and data mining and collection practices. The scope and size of Google as a corporation as well as its CSR priorities made this company an intriguing topic for this study. Google made a social responsibility commitment by establishing a philanthropic entity within the company which became known as Google.org - with a starting budget of $\$ 1$ billion (Hafner, 2006). Google.org was sanctioned to develop solutions to poverty, disease, and global warming (Hafner, 2006). This case study provides an opportunity to examine the philanthropic efforts of Google as a business and offers the chance to evaluate the potential benefits of corporate social responsibility for society.

Google has gained the reputation of the most-used search engine and the most-visited web site in the world (Conti, 2009). In 2009, Google served half of the entire internet population of 500 million (Conti, 2009). Its mission statement is both ambitious and ambiguous and has enabled Google to create a wide-range of services for the benefit of the public. Almost all of the services that are offered are free and are indeed, universally 
available to anyone with an internet connection and the internet browsing capability of a computing device. Since its incorporation, Google has grown to be more than just a search engine. Today it offers various communicating services, navigation services, advertising services, and diverse networking services, to include cloud technology. Personal convictions and beliefs of the company founders (Larry Page and Sergey Brin) were examined as relevant to significant decisions about business operation and its social responsibility actions. The education and background of both executives, as well as documented past actions, uncovered potential reasons for social responsibility interest at Google. This case study investigates the role and reasons behind CSR practices at Google and seeks to facilitate a platform for discussion in an effort to understand the role of CSR as initiated through Google's mission of, "To organize the world's information and make it universally accessible and useful." (Google, 2005). In order to move forward in this case study, we will now consider Google's services and operating mechanisms from a CSR perspective.

\section{PROBLEM DEFINITION}

\section{Background}

A significant part of Google.org is Google Foundation, a completely separate a non-profit segment with an endowment of $\$ 90$ million. Google Foundation is restricted by 501(c)(3) of the IRS code (Hafner,2006), and any profits Google.org made should result in the philanthropic segment of Google, not the search engine part of the corporation. Through establishing its philanthropic body Google tried to change the world's perception of philanthropy (Google, 2005). While nonprofit status is generally considered to be the right position for a socially responsible and charitable cause, it has its own issues (Whitehouse, 2003). The world has seen how management of philanthropic and charity organizations took advantage of their nonprofit status by engaging in insider dealings. For example, in 2003 a growing number of nonprofit charities and philanthropic organizations were accused of excessive spending: private aircrafts, hundreds of dollars in fees to board of trustees, unreasonably high bonuses, and costly perks for management (Price, 2007).

Corporate social responsibility requires companies to engage in activities good for society beyond that of their own economic interest (Ethical, 2003). It means that if these start-ups earn profit they also pay taxes. Yet, Google.org appeared to meet CSR requirements, at least partially (Colvin, 2009). Originally Google.org had promising plans to sponsor projects related to super efficient engines which would make 100 miles per gallon (Hafner, 2006) and by 2008, Google.org officially declared five areas of its work as socially responsible ventures: 1) predicting and preventing diseases, 2) stimulating growth of small and midsize businesses, 3) increasing access to information and public services, 4) developing renewable energy, and 5) helping to commercialize plug-in hybrids (Strom \& Helft, 2011).

The Establishment of Google.org reflected Google's commitment of doing good for society and was supposed to establish new businesses and projects for the benefit of humanity (Google, 2005). The socially responsible ventures that would result from Google.org would have had a competitive advantage because they were not expected to show profit (Hafner, 2006). Instead, these firms could focus on developing solutions for social issues such as education, disease, poverty, hunger, and climate change. To emphasize concern for doing good for society, Google founders hired a TED prize recipient, Dr. Brilliant, as the first executive of Google.org (Hafner, 2006). Dr. Brilliant received his prize for establishing a disease outbreak detection system, he advocated sustainability and public health access for humanity, and his impressive resume included work on polio vaccination projects in India and clean energy in China (Hafner, 2006).

As many of his colleagues admit, Dr. Brilliant had an incredible resume as an advocate for sustainability and humanity, yet he seemed to lack effective management skills (Strom \& Helft, 2010). The hiring of the TED prize recipient was seen by some as a carefully gauged public relations tactic. Dr. Brilliant was a philanthropy celebrity at this time, and his image could conceivably induce good publicity for Google's newborn enterprise. Although his management skills were not exactly known at the time of his hire, some of the first decisions made by Dr. Brilliant began to garner attention (Google.org, 2011). While company executives and Google founders Brin and Page were mostly traveling in the developing world and chose not to attend grant proposal meetings, Dr. Brilliant was left alone to make decisions (Strom \& Helft, 2011). For instance, Dr. Brilliant's own organization, InStedd, received one of the first, large sum grants awarded by Google.org which was valued at \$25 million (Strom \& Helft, 2011). Another organization that was co-founded by Dr. Brilliant also enjoyed significant financing of $\$ 2.5$ million (Strom \& Helft, 2011). There seemed to be little evidence for genuine corporate-wide involvement with the philanthropic body of Google (Commission, 2003). For the purpose of this case study, selected projects and pilots as examined will be discussed.

\section{Relevance and Responsibility of Philanthropy}

As expected, Google excelled in technology and innovation criteria for corporate social responsibility (Robbins \& Coulter, 2011). Google Earth Engine was a powerful earth observation platform with a goal to monitor forestation/deforestation on the planet. For two years, Google challenged itself to donate 20 million computer hours to continue development of the 
platform. This was a volunteer effort of Google to assist the United Nations Program on Reducing Emissions from Deforestation and Forest Degradation. One of the viable results of the project included forest cover and water mapping of Mexico for development of a project in which Google engineers partnered with South Dakota State University and the Mexico National Forestry Commission.

Google for Nonprofits project in collaboration with Google Online Marketing Challenge was working to encourage students across the world to work with local businesses and NGO's for effective online marketing campaigns. To stimulate participation, Google for Nonprofits provided free advertising using Google's AdWords service. In addition, Google committed to make a donation in the name of the winning students to the nonprofit partner. This project allowed organizations to receive more and larger donations, created jobs for the poor, raised awareness, and improved operations for nonprofits (The Market, 2006).

Another result of a high technology approach to philanthropy was Google Flu Trends. The project entailed a Flu Vaccine Finder which was a collaborative effort of Google.org and the U.S. Department of Health and Human Services. The effort allowed users to locate flu vaccine providers, promoted public user access information concerning flu outbreaks around the world, provided tips and recommendations for staying healthy, and helped prevent future bursts of disease by analyzing past data. An additional public health conscious pilot launched by Google.org was Health Speaks. This program aimed to provide relevant and credible health information online in local languages. Google.org successfully completed a community based translation of Wikipedia health articles from English to Arabic, Hindi, and Swahili. This initiative was funded by Google.org at a cost of .03 US cents per word translated. The list of participating institutions included the Cancer Hospital of Egypt, the Public Health Foundation of India, and the African Medical and Research Foundation. In 2010, Google direct donations equaled $\$ 145$ million to non-profits and academic institutions and more than $\$ 184$ in total donor contributions, as compiled from Google Grants, Google.org, and product support for non-profits (Google.org, n.d.).

\section{'Don't be Evil' and Empowering the Users}

For a long time Google was not making profits, due to the founders' perfectionist perception of the world (Strom \& Helft, 2011). It was not until 2001 that advertising became the primary revenue source for the corporation (Auletta, 2009). Even then, Google would not give up its priorities of social benefit for the users. In his book Googled: The end of the world as we know it, author Ken Auletta argues that the birth of AdWords as the revenue maker for Google was a revolution in the advertising business. Engineers at Googled devised algorithms that spared users biased-advertising results. What they did was allow users to decide which ads were more relevant by clicking on the advertising links. Instead of charging clients for questionably effective ads, Google allowed businesses to choose key words that would link their ads to the searches. Only when the user clicked on the ad would the client then be charged. The position of the advertisement itself would then be defined by the number of clicks an advertisement received from the end user. Effectively, Google was not overcharging businesses for ineffective ads (unclicked links) and avoided bias in their ad listings. For instance, wealthy clients had absolutely no chance to buy their way into the top of the ad listing, only users could decide position (Goldsmith \& Wu, 2008).

Many media corporations were outraged by the approach Google implemented (Conti, 2009). For example, envision multimillion dollar commercials during any given Super Bowl game - how would those media companies be charged for guaranteed return on their investment? It was difficult to identify in the world of Google. In traditional media advertising, benefits were tilted toward larger and wealthier companies as they could buy more air time, more printed space, afford flashier designs, and create expensive video commercials (Hillman \& Keim, 2001). With simple text ads, the 'fair paid per-click' model that Google established opened a new dimension of public-oriented advertising, where end-users, not insatiable marketing departments, became the ones who would decide popularity and placement. Google had implemented pure computer science and quantitative data to track effectiveness of its advertising (Corporate, n.d.). This kind of 'fair' advertising finally allowed smaller businesses to compete with gigantic corporations by implementation of equal rules (Auletta, 2009).

The trend of empowering the users, and therefore society, became a signature of Google (Goldsmith \& $\mathrm{Wu}, 2008)$. There remain obvious social responsibility roots in the foundation of the company (Hafner, 2006). From its incorporation in 1998 and steady growth, the culture of Google was diversified and enriched by topnotch specialists in the industry. As the company was expanding, executives realized the need to define corporate culture and wanted to come up with a set of rules for all employees (Moir, 2001). Eventually, all the suggestions were summarized as 'Don't be Evil' that evolved into a mantra for all deeds at Google (Auletta, 2009). Google gained the reputation of an ethically sympathetic business, which was also considered a unique competitive advantage. As some scholars argue, socially responsible corporations attract investors and consumers (Price, 2007). Google's 'Don't be Evil' approach remains an assertive attempt to create stakeholder value. 


\section{ANALYSIS OF RECENT RESEARCH AND PUBLICATIONS}

\section{Humanitarian Values and Profit}

Many scholars point out that younger corporate executives who take over business now are predisposed to seek deeper meaning in their work due to their background and personal experiences of turbulence in the 1960s and 1970s (Abowd, Milkovich, \& Hannon, 1990; Price, 2007). Larry Page confessed that in his childhood, fascination with computer science made him realize that he not only wanted to invent things, but that he could also change the world (Auletta, 2009). Mr. Page and Mr. Brin were not just children of turmoil; they remain vivid examples of strong opposition to monopolistic and profit-oriented giant corporations (Bagnoli \& Watts, 2003). Long before Google was established, Microsoft was the king of the paid services on the personal computer market. Page and Brin were convinced that users should be the kings (Auletta, 2009). Moreover, response to human rights and prior censorship in China also reflected strong condemnation of the oppressive regimes by executives of Google. Sergey Brin and his family were directly affected by the once oppressive communist regime of the Soviet Union (Scheffer \& Kaeb, 2011). Both founders saw a higher meaning in the mission of the company than just making the world information universally available for society. This unprecedented approach to business propelled them to the top of the technology business (Colvin, 2009).

In today's world, Google is the king of information. In just years five of business, Google had twice as many users as Yahoo and three times the number of users for Microsoft search engine (Auletta, 2009). In their book, Who controls the Internet?, Goldsmith and $\mathrm{Wu}$ wrote that one of the most effective ways to restrict information is through obtaining control over information intermediaries, such as Google (Goldsmith $\& \mathrm{Wu}, 2007)$. The authors argued that because search engines are gateways for information, they have effective means of controlling what the end user retrieves from the Internet. 'Search' is a powerful tool in the contemporary world. At Google, executives realize the importance of information gathering. During his speech to the Stanford Class of 2012, Larry Page said, "If you solve search that means you can answer any question, which means you can do basically anything." (Auletta, 2009).

Initially, the purpose of Google.org was to propel pioneering sustainable businesses and create partnerships for the good of the society. At Google philanthropy, activism turned into an additional way to differentiate business from that of other companies (Ethical, 2003). The business concept subsequently applied to a CSR cause resulted in Google.org being spared the traditional constraints normally surrounding nonprofit organization and operation (Strom \& Helft,
2011). Despite the philanthropy stance of Google.org's structure and its overall mission positioned to benefit society, there were still questions about the 'for profit' status of Google.org (Colvin, 2009).

Although some philanthropy ambitions at Google.org failed, there remained many philanthropic efforts that were garnered as quite successful (Google.org, 2011). It appeared that few companies were driven by innovation and growth in a way that paralleled that of Google and Google.org (Google.org, n.d.). Most of these socially responsible undertakings relate to the means of Google as a high technology company. An overwhelming number of the engineering and technology related projects that focused on social responsibility were established by Google.org (Colvin, 2009). Hannah Jones, Vice-President for corporate social responsibility at Nike, was one of many executives of top performing corporations who recognized that social responsibility widens horizons for innovation and growth (Price, 2007).

\section{Human Capital and Creativity}

One aspect of CSR at Google included hiring and employee retention processes as implemented at Google. This was relevant due to the size of the company and its growing international presence. According to the company's Annual report of 2010, Google had 24,400 full-time employees spread over 50 countries across the world. Through such a massive employee base, Google indirectly affected thousands of family households around the globe and these effects were encouraged under the concept of CSR (Mitchell, 1992). Google allowed room for creativity and recognized invaluable contributions by its employees. For example, Google spent \$70 million on food for their employees (Auletta, 2009). Sustainability on the Google campus was part of famous food and beverage establishments on Google campus. Today, the Google campus boasts employee restaurants that support local farmers within a 180 miles radius (Auletta, 2009). While there are many reasons why talented individuals would want to work for Google, it remains clear that an informal and open culture, fair treatment of employees, and the overall commitment to 'Don't be Evil' continue to be important factors of recruitment and retention (Whitehouse, 2003).

Executives at Google believed that the unique talent and creativity became evident in employees who felt that their work was meaningful and helped them to make the world a better place (Auletta, 2009). For that reason, Google allowed its talent (human capital) to experience their creativity and innovation using Google's abundant resources. At Google, one day per week employees were free to pursue projects they are passionate about. This unconventional treatment of talented employees paid off. Many of the individual employee projects turned into full products and services at Google, such as Google News, Orkut, and Google Suggest. For example, 
after the events of 9/11 Google employee Bharat Krishna was concerned that the general population in the United States lacked comprehension of other cultures, religions, and important events in the world (Auletta, 2009). He wanted to create a way for people in the U.S. to connect with the worldwide issues and news. The Google News project was Kirshna's initiative and when first launched, was an international news hub without distracting advertisements. Google lost money on the project, but did retain ownership because in the end, Google News served a good purpose (Google.org, n.d.).

However, a specific obstacle to the initial success of the Google.org philanthropic arm was the engineeroriented culture at Google. Google.org soon found itself isolated and by 2009, many executives hired specifically for Google.org had left the organization (including Dr. Brilliant), and eventually the remaining corporate employees gave a very poor morale rating to the philanthropic segment of the company (Strom \& Helft, 2011). When Google as a parent company finally decided to reorganize and review all projects, multiple grants had been suspended or were cancelled (Strom \& Helft, 2011). There was evidence that a business-like approach to philanthropy did not work well at Google.org. Whether or not Google.org should have been entirely nonprofit was a question of a long debate. What appeared to be more important was how successful Google.org was in implementing its goals. After five years of philanthropic experiments, Google.org resulted in nothing more than an extension of Google's engineering projects (Strom \& Helft, 2006). The issue appeared to be rooted in the internal culture and organization culture that comprised Google.

\section{Social Responsibility and Hidden Interests}

Indeed, Google originated as a search engine but today this company has infiltrated into our lives on multiple levels. The search is ultimately a tool for data collection and analysis. Due to the nature of Google's business, it is important to understand a portion of the mechanisms Google uses to offer its services. As a search engine and information intermediary, Google continues to have a huge influence on how people receive information. Enjoying absolute dominance worldwide, Google alone has potential to restrict access to certain kinds of information (Goldsmith \& Wu, 2008). A user query does not necessarily generate information that initially triggers the recognition that information has been restricted. This is in part due to the fact that the search engine itself is the gateway for information on the Internet for the end user (Goldsmith $\& \mathrm{Wu}, 2008)$.

A simple change in the way search results are identified potentially may have an enormous effect on the quality and content of information that end users are getting. If a search engine fails to provide trustworthy services, it reflects poor social responsibility of the company and potentially can harm its public image and reduce shareholder value. In their book, Goldsmith and $\mathrm{Wu}$ depict sample human rights violation cases when a search engine company effectively applied their filtering means to serve governmental interests. In 1999, Yahoo expanded its business to China. Upon establishment of its operation in China, Yahoo received request from the Communist Party of China to filter out any materials that 'might be harmful or threatening to Party rule' (Goldsmith \& Wu, 2007). In 2002, Yahoo complied with the request, due to the threat of losing the right to operate in the tempting large market of China. What was the result? By 2004, Yahoo received tarnishing publicity and was labeled as a Chinese policy auxiliary. Shares fell from $\$ 475$ in 2000 to $\$ 9.71$ in 2002 (Goldsmith $\& \mathrm{Wu}, 2007)$. While social responsibility investment may not have directly affected stock prices, an example of poor social responsibility was associated with a significant decline in shareholder value.

Perhaps the most significant impact of Yahoo's compliance with a filtering request was the case of a Chinese journalist imprisonment (Goldsmith \& Wu, 2007). In the fall 2005, Shin Tao sent an email using his Yahoo account to a democratic web site in the United States. The email contained a recording of the meeting where the Communist Party discussed how they wanted to deal with the Tiananmen Square anniversary. Once the Chinese government recognized the information leak, they asked Yahoo to help in identifying the sender. Yahoo handed out requested information about identity of its user to the authorities, which resulted in the 10 year imprisonment of the journalist. This was a vivid example of how social responsibility values had been ignored by a web company. While this was an example of a different company than Google, it serves as an example of why there are ethical concerns associated with the power to control information. Although Yahoo was seen as a company that allegedly supported the Chinese government's violation of human rights, Google, Inc. also faced ethical dilemmas in China. In 2002, Google launched the Chinese version of its search engine (Auletta, 2009). In 2005, the Chinese Government demanded that Google monitor the search results made in China; Google complied (Auletta, 2009). Even though there was no reported case of a direct adverse impact for individual users, as in the Yahoo case, it conveyed a negative message about the 'Don't be Evil' motto of Google.

\section{FORMULATION OF ARTICLE OBJECTIVES}

\section{Ethics and Power}

In the world of business, it remains difficult to know genuine reasons for certain actions, which are times are vital components of business plans. Opponents of corporate social responsibility argue that CSR is nothing 
more but a show - nothing more than a cosmetic treatment (Price, 2007). It took Google four years to rethink its approach of doing business in China which resulted in the recovery of its 'be good' values. By 2009, Google executives seriously questioned the ethical impact of censoring searches and consequently refused to comply with Chinese censorship laws (Auletta, 2009). After shutting down their servers in China on March 22, 2010, Google released a statement: "We don't want to engage in political censorship. This is especially true in countries like China and Vietnam that do not have democratic processes through which citizens can challenge censorship mandates." (Scheffer \& Kaeb, 2011). For any business, it may prove difficult to resist the potential market of 1.5 billion people in China (Auletta, 2009). What surfaces as an important component in the discussion of CSR in this scenario is that while Google complied with its own definition of corporate social responsibility, it also progressively engaged in a counterattack measure against oppressive governments (Scheffer \& Kaeb, 2011).

Google's Corporate Social Responsibility website lists multiple philanthropy related projects in China. One of them is Google China Social Innovation Cup for College Students. This project encourages college students to address social issues in China. In 2008, 1,245 proposals resulted in 32 winners who were identified to receive awards of up to $\$ 11,700$ to support their efforts in social innovation. In 2011, Google China Social Innovation Cup received an astonishing 3,326 applications. For that year, 40 expected winners were awarded $\$ 3,000$ - $\$ 12,000$ to fund proposed social missions. In his statement, Dr. Eric Schmidt, CEO of the company, expressed satisfaction with the results of the program and vocalized that the perspective of students in China remains crucial to solving big social issues.

After this ethics lesson from China, Google cemented its 'Don't be Evil' concept into its business strategy (Welford, 2004). Not only in Google.org but also into the heart of its business Google refused to surrender its integrity and values of what it means to be a socially conscious company. Their unbiased and relevant search and Adwords fair advertising services remain in-line with Google values. While it is true that Google openly condemns government censorship and advocates for human rights in China, there is still uncertainty about the way Google could use the tremendous amount of information from users all over the world. To understand the seriousness of the issue, it remains important to recognize the clear distinction between privacy laws applied to personal data on one's own computer and information that one voluntarily provides to a third party. In the first scenario, personal data is protected under the Fourth Amendment, while in the second scenario, control over personal information is very limited and becomes even more restrictive once one becomes a registered user (Conti, 2009).

\section{Being a Transnational Company}

While social responsibility became part of Google internal culture as a transnational high technology business, Google continued to impact communities beyond the internal corporate level. For example, when looking at the actual business impact of the corporation in relation to social responsibility, Google's mission of 'organizing world information and making it universally available' is a very ambitious task. Nevertheless, Google's search engine has proven itself as the mostused worldwide source of immediate information (Conti, 2009).

Google continues to invest over $\$ 3$ billion into its computer infrastructure worldwide (Auletta, 2009). This massive computing technology is necessary for more advanced operations than just text searches (Auletta, 2009). What Google does with information from the searches is the primary reason for advanced technological capacity. From the initial search engine in 1998 to the present day, Google has evolved into a powerful networking technology giant. After the first IPO in 2004, Google added a wide range of services to its business : Gmail, AdWords, AdSense, Google Earth, Picasa, Google Maps, Google News, Google Books, Youtube, Latitude, Google Translate, Blogger, Reader, Scholar, and Google + . This does not include the assortment of mobile services for Android OS and other developing programs and services.

Google.org is still a nonprofit-oriented business promoting engineering projects such as Flu Trends, Vaccine Finder, Google Earth Engine, Health Speaks, and many more. An endless lineup of services may be seen as tools that make our lives easier. While serving Google's mission to organize the world information and make it universally available, these tools also collect data from users all over the world. To process and analyze this information, Google invests heavily into its computing infrastructure. This information is what makes Google so powerful. Users' searches are recorded, as well as emails that are retained for extended periods of time on Google servers (Conti, 2009). Using the data from previous searches, Google is able to offer faster and more relevant search results. As a reminder, Google is the most relied on search engine in the world. This means that Google incessantly collects information about the most number of users worldwide (Conti, 2009).

As a result of technological developments, cloud computing represents a very lucrative area for Google (Scheffer \& Kaeb, 2011). The technology offers users the convenience of storing and editing virtually any data content on corporate servers. In reality, this means that corporations like Google need more than ever to earn users' trust. Google is determined to continue their strategy of 'Don't be Evil' to win the battle for the market share. A very big leap forward was an assertive resistance to a foreign government attempt to violate 
norms of international law and human rights on the case of China. In 2010, a security team of Google identified politically motivated cyber attacks coming from Vietnam against corporate servers (Scheffer \& Kaeb, 2011). On its corporate blog, Google released another statement in support of corporate socially responsible values and condemned use of malicious software to suppress opinions of dissent. Such practice of transparency and assertive advocacy for equal distribution of information appears to convey that Google continues to apply high standards for security and ethical treatment of information provided to and by users.

\section{FORMULATION OF KEY FINDINGS}

\section{CSR and Identity}

Google has built a strong foundation for corporate social responsibility. According to studied materials, a publicly announced commitment to philanthropy was not just a single public relations campaign. Despite the first efforts in philanthropy being challenging, Google found a way to adjust and incorporate CSR throughout its operation (Strom \& Helft, 2011). Founders established commitment to social responsibility by initiating the Google Foundation and Google.org. In this instance, CSR functioned as the mission-defining tool for both Google.org and the Google Foundation. The outcomes were philanthropy projects that benefitted individuals, nonprofit organizations, and small businesses around the world. These benefits included financial support and development of customized services to help humanitarian ventures tackle world issues. On the internal corporate level, Google adopted sustainable ways of doing business, such as solar panels, 'green' buses, and sustainable food utilization. In this manifestation, Google's CSR's function is to build a sustainable infrastructure within the company. Personal beliefs and views of Larry Page and Sergey Brin played a crucial role in development of CSR values at Google. Both founders believed in the deeper meaning of their work.

From this perspective, CSR laid the foundation for the business strategy and corporate values (World, 1999, 2000). This is the primary reason that Google continues to offer services and products that empower users and gain trust. The company proved its commitment to ethical values by counterattacking censorship and violation of human rights. Evidence provided in the study also conveyed ways that Google's CSR approach positions itself as different from other companies in the industry, resulting in a creation of higher value for stakeholders (Bagnoli \& Watts, 2003). In this case, CSR provided Google with the resolve for ethical advocacy. Ideals that started Google were also reflected in the corporate culture and employee retention (Barnard, 1938). Management at the company recognized that employees were the most valued assets and treated them accordingly. From this angle, CSR is an employee retention and empowerment tool. Moreover, Google embraced the individual passions of its employees and allowed them to pursue their individual projects. This in turn enabled the talent at the company to contribute with socially responsible products for the company. This characteristic made CSR a force of innovation and creativity.

While Google was prioritizing its development of technological infrastructure, the other precious asset was trust of users. In the wake of the networking era in technology, social responsibility became an even more important issue of identity for Google. At that point, CSR also became a tool for risk management. While recent studies suggest that Google continues to seek other ways to engage in social responsibility action, there is already a strong CSR foundation in place that gives Google an advantage when competing for public trust (Google.org, n.d.). The conducted case study brings to a conclusion that the triumph of CSR at Google rests in multidimensional and incessant application of CSR throughout the organization (Sen \& Bhattacharya, 2001). CSR at Google became a priority as aligned with its core mission, corporate and employee culture, founders' beliefs, and product development. This case study also revealed that in order to achieve the best results in corporate social responsibility, effort needs to be applied throughout multiple levels within the organization. Although the study revealed a strong connection between CSR and internal developmental factors (business projects, products, services, management, employees, and corporate culture), more focus is needed to facilitate discussion on how successful CSR effort was at Google in regards to satisfying external parties, such as clientele, users, and shareholders.

\section{QUESTIONS FOR DISCUSSION}

1) Can an organization such as Google be considered a socially responsible arm of a for-profit parent company?

2) Many analysts argue that corporations are neither capable nor qualified for social and environmental projects (Price, 2007). Perhaps the fact that Google failed to live up to its own expectations in philanthropy adds fuel to this argument. How was Google.org philanthropy an actual philanthropy, per se, if it could make money?

3) Why should any publicly traded and profit-oriented company be competent in philanthropy?

4) There is still great potential in the sustainable energy projects that Google embraces. Engineers of the company continue to work on renewable and solar energy projects. Work on that area of social responsibility continues to be of personal interest for 
founders Larry Page and Sergey Brin (Strom \& Helft, 2011). What is it about sustainable energy that fascinates Google executives? Was it the age and culture in which founders were born? Does that incident mean that Google's humanitarian values and executives' purist view on the world has disappeared?

5) Undeniably, there remains a strong corporate-wide commitment to clean energy. For example, Google installed solar panels on the roofs of its buildings. In fact, today Google has the largest solar powered corporate campus in the USA (Auletta, 2009). Google also uses solar generated energy to charge its fleet of hybrid cars and offers subsidies of $\$ 3,000$ - $\$ 5,000$ to employees who purchase hybrids (Auletta, 2009). Could it be concluded that Google's capacity for social responsibility was exhausted by its computer and engineer driven culture?

6) What is the relationship between social responsibility and 'search'? How certain can we be that when we use search engines, such as Google, Yahoo, AOL, etc. that the information is not eventually used to serve hidden interests?

7) This creates an uncertainty about the ethical value for the public from the services of a single powerful search engine such as Google. Is it for the good of society to allow a single company to have so much power of distribution as relative to all Internet information?

8) While CSR may attract investors and consumers alike, there is another important dimension of CSR that should not be overlooked. What was the role of corporate social responsibility at Google and how successful was the company at applying CSR practices to its business? Has corporate social responsibility turned into an important tool for retention, motivation, and recruiting of talent?

9) What makes Google the most used search engine in the world? At the end of the day, can users worldwide chose to trust Google and believe that their information will be protected?

\section{CONCLUSIONS AND RECOMMENDATIONS}

What inspires a person to become involved in a community or civic service type of organization? After completion of this case study, the authors would like to propose a related and collaborative case study that would continue on a smaller, global level to seek to provide information for additional discussion on the following topics that could be approached from different cultural stand points. Being community and civically engaged can occur in the workplace, and outside the actual work facility. But from where does the desire to engage in CSR activities and efforts come? Suggestions might include from an inside-type learned environment such as tradition or a duty to family or society, or even a personally endorsed standpoint such as an obligation. If potential employees are looking to join CSR companies as an extension of their personal identity, could this be influenced by 'influencing' factors in their lives such as peer pressure, craving a sense of belongingness, paying a debt to society, or giving back to make a difference? Some portions of CSR attempt to measure or gauge an individual's involvement in the community and/or civic engagement. Apart from the work environment, there are individuals who desire to continue an involvement in CSR because they either knowingly or unknowingly engage in theories such as those from psychological, sociological, or economical (i.e. rational choice theory, decision theory, free rider theory).

The country of Uzbekistan might provide a specific focus for a collaborative study on personal involvement in CSR as a derivative from the aforementioned theories. Basic information regarding access to certain types of internet research is easily accessible via an outside internet resource. Censorship or filtering of information appears in colonial languages that have entangled countries such as Uzbekistan through isolation and assimilation. As internet access and connectivity becomes increasingly accessible and accepted as a way of life, social networking encourages a universal conversation that is eager to explore a more diverse cultural landscape. In an effort to encourage and explore dialogue, the authors are of the opinion that a collaborative case study will provide a fertile platform of communication for students and scholars who are eager to discuss CSR.

\section{REFERENCES}

Abowd, J., Milkovich, G., \& Hannon, J. (1990). The effects of human resource management decisions on shareholder value. Industrial and Labor Relations Review, 43, 203 236.

Auletta, K. (2009). Googled: The end of the world as we know it. New York, NY: The Penguin Press.

Bagnoli, M., \& Watts, S. (2003). Selling to socially responsible consumers: Competition and the private provision of public goods. Journal of Economics and Management Strategy, 12, 419-445.

Baron, D. (2001). Private politics, corporate social responsibility and integrated strategy. Journal of Economics and Management Strategy, 10, 7-45.

Business for Social Responsibility (2000). Introduction to corporate social responsibility. Retrieved from http://www.khbo.be/ lodew/Cursussen/4eingenieurCL/T he\%20Global\%20Business\%20Responsibility\%20Resour ce\%20Center.doc

Colvin, G. (2009). The world's most admired companies 2009. (Cover story). Fortune, 159, 75-78.

Commission of the European Communities (2003). What is corporate social responsibility (CSR)? Retrieved from http://europa.eu.int/comm/employment_social/socdial/csr /csr_whatiscsr.htm

Conti, G. (2009). Googling security: How much does Google know about you? Crawfordsville, IN: Addison-Wesley 
Pearson Education.

Corporate information - everything Google. (n.d.). Retrieved from http://www.google.com/intl/en/about/corporate/ index.htm

Corporate social responsibility - Google. (n.d.). Retrieved from http://www.google.com/intl/zhCN/corporate/ responsibility_en.html

Ethical Performance (2003). Introduction: Defining corporate social responsibility. Retrieved from http://www.ethical performance.com/bestpractice/archive/1001/introduction. html

Frederick, W.C., Post, J.E., \& Davis, K. (1992). Business and society - management: Public policy, ethics (7th ed.). New York: McGraw-Hill. Retrieved from http://www.studyblue.com/notes/note/n/mgt-340chapters-5910-vocab-/deck/2239796

Friedman, M. (1970, September 13). The social responsibility of business is to increase its profits. The New York Times.

Goldsmith, J., \& Wu, T. (2008). Who controls the internet? New York, NY: Oxford University Press.

Google annual report 2004. (2005). Retrieved from http://investor.google.com/pdf/2004_google_annual_repo rt.pdf

Google, Inc. (2010). Google Is Blocked in 25 of 100 Countries. (n.d.). Retrieved from http://seekingalpha.com/ article/199526-google-is-blocked-in-25-of-100-countriesthey-offer-products-inn

Google.org recent philanthropic updates (2011). (n.d.). Retrieved from http://www.google.org/news/2011/jan/

Google.org struggles to measure up to goals (2011). (n.d.). Retrieved from http://foundationcenter.org/pnd/ news/ story.jhtml?id=324800008

Hafner, K. (2006). Philanthropy Google's way: Not the usual. The New York Times. Retrieved from www.nytimes.com/2006/09/14/technology/14google.html ?pagewanted $=$ all

Hillman, A., \& Keim, G. (2001). Shareholder value, stakeholder management, and social issues: What's the bottom line? Strategic Management Journal, 22, 125-139.

Kilcullen, M., \& Kooistra, J.O. (1999). At least do no harm: Sources on the changing role of business ethics and corporate social responsibility. Reference Services Review, 27, 158-178.

Mitchell, R.N. (1992). Corporate social responsibility. British Food Journal, 94, 38-44.

Mehta, N. (2010). Google online security blog: The chilling effects of malware. Retrieved from googleonlinesecurity. blogspot.com/2010/03/chilling-effects-of-malware.html

Moir, L. (2001). What do we mean by corporate social responsibility? Corporate Governance, 1, 16-22.

Piga, C. (2002). 'Corporate social responsibility: A theory of the firm perspective. A few comments and some suggestions. Academy of Management Review, 27, 1315.

Price, T. (2007, August 3). Corporate social responsibility. CQ Researcher, 17, 649-672. Retrieved from http://library.cqpress.com/cqresearcher/

Products - everything Google. (n.d.). Retrieved from http://www.google.com/intl/en/about/products/index.html

Robbins, S.P., \& Coulter, M. (2011). Management (11 ed., p. 125). Upper Saddle River, NJ: Prentice Hall.

Sen, S., \& Bhattacharya, C.B. (2001). Does doing good always lead to doing better? Consumer reactions to corporate social responsibility. Journal of Marketing Research, 38, 225-243. Retrieved from http://www.jstor.org/ stable/1558626

Strom, S., \& Helft, M. (2011). Google finds it hard to reinvent philanthropy. The New York Times. Retrieved from http://www.nytimes.com/2011/01/30/business/30charity.h tml? pagewanted=all

Top visited websites in the Russian speaking/commonwealth of Independent States (2013). Retrieved from http://vkontakte.ru/; http://www.odnoklassniki.ru/

Welford, R. (2004). Corporate social responsibility in Europe and Asia: Critical elements and best practice. The Journal of Corporate Citizenship, 13, 31-47.

Whitehouse, L. (2003). Corporate social responsibility, corporate citizenship and the global compact: A new approach to regulating corporate social power? Global Social Policy, 3, 299-318.

Widely used Russian search engines (2013). Retrieved from www.Yandex.ru; www.mail.ru; www.rambler.ru

World Business Council for Sustainable Development (1999). Corporate social responsibility: Meeting changing expectations. World Business Council for Sustainable OUT THE AUTHORS Development: Geneva.

World Business Council for Sustainable Development (2000). Corporate social responsibility: Making good business sense. World Business Council for Sustainable Development: Geneva. 


\section{ABOUT THE AUTHORS}

Corresponding author: Dr. Sharon K. Kendrick, email: skendrick2927@gmail.com.

Dr. Sharon K. Kendrick - serves as Director of Resort and Club Management in Reeves School of Business, Methodist University. Kendrick has been teaching hospitality, culinary, and business classes for almost two decades. In addition to prior employment in the hospitality and business industry, her professional work experience includes emergency management and community safety. She is trained in disaster preparedness and risk management, and engages in social responsibility activities through local community-focused groups such as Rotary, Woman's Club, Daughters of the American Revolution, and faith-based associations. Kendrick has traveled and studied abroad maintaining contact with her international student family.

Dr. Mark C. Kendrick - has been teaching marketing, business, and human resource management for over two decades. His professional interests encompass politics, public service, and community/service engagement. Kendrick is currently Director of Community Engagement Programs and is a Sam Walton Fellow in the Reeves School of Business at Methodist University. Kendrick serves as the primary faculty advisor for the American Marketing Association Collegiate Chapter and ENACTUS. Since 2013, his student community engagement teams have closed-out over 50 projects that include rewriting the awards qualifications and selecting recipients for the Fayetteville Regional Chamber of Commerce Awards Gala.
Anastasiya Saakova - graduated with summa cum laude honors from Methodist University in 2013, where she earned her Bachelor of Arts degree. Her primary areas of interest are corporate social responsibility and global trade and development. Anastasiya is originally from Uzbekistan and is thrilled for the opportunity to contribute her first scholarly article to a publication that examines her native region. Anastasiya is a member of various honor societies including Delta $\mathrm{Mu}$ Delta Business Honor Society and Omicron Delta Kappa Leadership Honor Society. Learning and living in the $\mathrm{Li}$ Po United World College of Hong Kong forged her commitment to intercultural understanding, sustainability, and idealism. She currently works for a non-profit organization dedicated to raising awareness of survivability and early detection of breast cancer 